\title{
TRANSIENT DYNAMICS OF COMPOSITE SANDWICH PLATES USING 4-, 8-, 9-NODED ISOPARAMETRIC QUADRILATERAL ELEMENTS
}

\author{
T. KANT and MALLIKARJUNA \\ Department of Civil Engineering, Indian Institute of Technology, Powai, Bombay 400 076, India
}

Received February 1988

Revised January 1989

\begin{abstract}
A finite element method based on Mindlin's theory is employed in the prediction of the dynamic transient response of multilayered composite sandwich plates. Numerical convergence and stability of 4-noded linear, 8-noded serendipity, and 9-noded Lagrangian elements are established using an explicit time integration technique. A special mass matrix diagonalization scheme is adopted which conserves the total mass of the element and includes the effects due to rotary inertia terms. The parametric effects of the time step, finite element mesh, lamination scheme, and orthotropy on the transient response are investigated. Numerical results for deflections and stresses are presented under various boundary conditions and loadings. The results presented herein should be of interest to composite-structure designers, experimentalists, and numerical analysists in verifying their results.
\end{abstract}

\section{Introduction}

The high strength and stiffness versus weight obtainable in sandwich panels has led to a wide variety of applications. Most structures, whether they are used in land, sea, or air, are subjected to dynamic loads during their operation. There exists a need for assessing the transient response of laminated plates. However, transient analyses of composite sandwich plates of finite dimensions have not received adequate consideration.

A large amount of literature has been devoted to the development of theories for conventional sandwich structures and to the study of their static and dynamic behaviours by analytical and numerical methods. A detailed historical review is given in the books by Plantema [19] and Allen [2] and in two papers by Habip [4,5]. The pioneer workers are Reissner [22-24], who also studied the finite deflection problem, and $\mathrm{Yu}$ [27-30], who published a series of papers on vibrations of sandwich plates including viscous damping and large deflections. Exact elasticity solutions for some particular sandwich plate bending problems were obtained by Pagano [17]. Many researchers have adopted the versatile finite element method in analysing conventional sandwich and laminated plates (e.g. see $[1,15]$ for sandwich plates and $[6,10,16,18]$ for laminated plates). Khatua and Cheung $[11,12]$ successfully solved a variety of linear problems for multilayer plates and shells using non-conforming rectangular and triangular plate and shell finite elements. All of these studies were confined to either static analyses or free-vibration analyses.

In the present paper, transient response of layered, composite sandwich plates is investigated using a shear deformable finite element. The present study is the first to consider the transient response of sandwich plates of arbitrary construction and finite dimensions. 


\section{Theory and formulation}

A multilayered sandwich plate, as shown in Fig. 1, having $n$ stiff faces and $n-1$ soft cores is considered. The displacement field of such a plate can be assumed to be

$$
\begin{aligned}
& u(x, y, z, t)=u_{0}(x, y, t)+z \theta_{x}(x, y, t), \\
& v(x, y, z, t)=v_{0}(x, y, t)+z \theta_{y}(x, y, t), \\
& w(x, y, z, t)=w_{0}(x, y, t),
\end{aligned}
$$

where $t$ is the time and $u, v$, and $w$ are the displacements in the $x, y$, and $z$ directions, respectively, of any generic point in the plate space. The variables $u_{0}, v_{0}$, and $w_{0}$ are the associated midplane displacements; and the parameters $\theta_{x}$ and $\theta_{y}$ are the rotations of the normals to the midplane in the $x-z$ and $y-z$ planes due to membrane-flexural deformations.

The strain expressions derived from the displacement model of equation (1) are:

$$
\begin{aligned}
& \varepsilon_{x}=\varepsilon_{x 0}+z \chi_{x} ; \quad \varepsilon_{y}=\varepsilon_{y 0}+z \chi_{y} ; \\
& \gamma_{x y}=\varepsilon_{x y 0}+z \chi_{x y} ; \quad \gamma_{y z}=\phi_{y} ; \quad \gamma_{x z}=\phi_{x} ;
\end{aligned}
$$

in which

$$
\begin{aligned}
& {\left[\varepsilon_{x 0}, \varepsilon_{y 0}, \varepsilon_{x y 0}\right]=\left[\frac{\partial u_{0}}{\partial x}, \frac{\partial v_{0}}{\partial y}, \frac{\partial u_{0}}{\partial y}+\frac{\partial v_{0}}{\partial x}\right],} \\
& {\left[\chi_{x}, \chi_{y}, \chi_{x y}\right]=\left[\frac{\partial \theta_{x}}{\partial x}, \frac{\partial \theta_{y}}{\partial y}, \frac{\partial \theta_{x}}{\partial y}+\frac{\partial \theta_{y}}{\partial x}\right],} \\
& {\left[\phi_{x}, \phi_{y}\right]=\left[\theta_{x}+\frac{\partial w_{0}}{\partial x}, \theta_{y}+\frac{\partial w_{0}}{\partial y}\right] .}
\end{aligned}
$$

The stress-strain relations for a typical layer $L$ with reference to the material axes $(1-2-3)$ are given by

$$
\begin{aligned}
& {\left[\begin{array}{l}
\sigma_{1} \\
\sigma_{2} \\
\tau_{12}
\end{array}\right]^{L}=\left[\begin{array}{ccc}
C_{11} & C_{12} & 0 \\
C_{12} & C_{22} & 0 \\
0 & 0 & C_{33}
\end{array}\right]^{L}\left[\begin{array}{c}
\varepsilon_{1} \\
\varepsilon_{2} \\
\gamma_{12}
\end{array}\right]^{L},} \\
& {\left[\begin{array}{l}
\tau_{23} \\
\tau_{13}
\end{array}\right]^{L}=\left[\begin{array}{cc}
\alpha C_{44} & 0 \\
0 & \alpha C_{55}
\end{array}\right]^{L}\left[\begin{array}{l}
\gamma_{23} \\
\gamma_{13}
\end{array}\right]^{L},}
\end{aligned}
$$
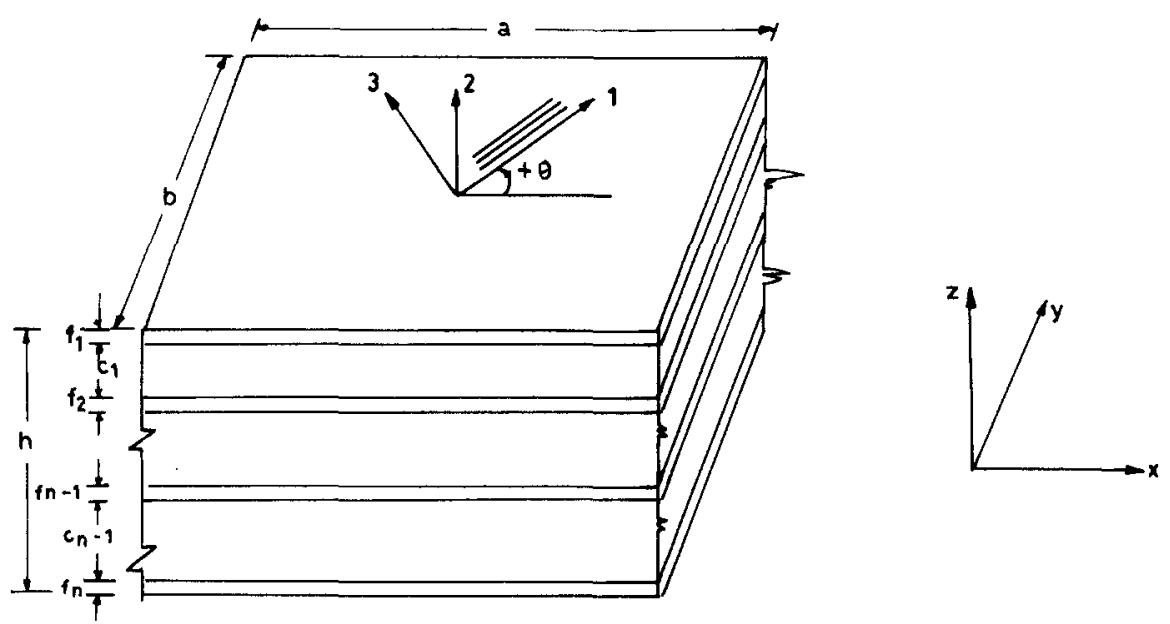

Fig. 1. Multilayer arrangement. 
in which $\left(\sigma_{1}, \sigma_{2}, \tau_{12}, \tau_{23}, \tau_{13}\right)$ are the stress and $\left(\varepsilon_{1}, \varepsilon_{2}, \gamma_{12}, \gamma_{23}, \gamma_{13}\right)$ are the linear strain components referred to the material axes (1-2-3) as shown in Fig. 1, and $C_{i j}$ 's are the plane stress reduced elastic constants of the $L$ th lamina and these are related to the engineering elastic constants [9]. The coefficient $\alpha$ has been given various values by different authors; e.g., $\alpha=2 / 3$ according to Timoshenko [25], Reissner [21] assumes a value of $\alpha=5 / 6$, and Mindlin [14] uses $\alpha=\pi^{2} / 12$, which is very close to the value used by Reissner. Unless otherwise stated, the value used throughout this work is Reissner's value of $\alpha=5 / 6$ for stiff face layers and unity for core material.

Following the usual transformation rule of stresses/strains between the layer (material) and the plate coordinate systems [9], the stress-strain relations for the $L$ th layer in the plate coordinate, $(x, y, z)$ are written in a compacted form as

$$
\boldsymbol{\sigma}=Q \varepsilon,
$$

in which $\sigma=\left(\sigma_{x}, \sigma_{y}, \tau_{x y}, \tau_{y z}, \tau_{x z}\right)^{\mathrm{T}}$ and $\varepsilon=\left(\varepsilon_{x}, \varepsilon_{y}, \gamma_{x y}, \gamma_{y z}, \gamma_{x z}\right)^{\mathrm{T}}$ are the stress and strain vectors with respect to the plate axes, and

$$
\boldsymbol{Q}=\left[\begin{array}{cc}
\boldsymbol{Q}_{i j} & \mathbf{0} \\
\mathbf{0} & \boldsymbol{Q}_{l m}
\end{array}\right] \begin{gathered}
i, j=1,2,3 \\
l, m=4,5
\end{gathered}
$$

are the transformed reduced elastic constants in the plate axes of the $L$ th layer.

The constitutive relations involving membrane forces, bending moments and shear forces are defined as:

$$
\left[\begin{array}{c}
N_{x}, N_{y}, N_{x y} \\
M_{x}, M_{y}, M_{x y} \\
Q_{x}, Q_{y}
\end{array}\right]=\sum_{L=1}^{n} \int_{h_{L}}^{L+1}\left[\begin{array}{c}
\sigma_{x}, \sigma_{y}, \tau_{x y} \\
z \sigma_{x}, z \sigma_{y}, z \tau_{x y} \\
\tau_{x z}, \tau_{y z}
\end{array}\right] \mathrm{d} z
$$

Upon integration, these expressions are rewritten in a matrix form which defines the stress-resultant/strain relations of the sandwich plate and is given by, $\bar{\sigma}=\boldsymbol{D} \bar{\varepsilon}$,

$$
\left[\begin{array}{c}
N \\
\bar{M} \\
\bar{Q}
\end{array}\right]=\sum_{L=1}^{n}\left[\begin{array}{ccc}
Q_{i j} H_{1} & Q_{i j} H_{2} & 0 \\
\hdashline Q_{i j} H_{2} & Q_{i j} H_{3} & 0 \\
\hdashline 0 & 0 & Q_{m l} H_{1}
\end{array}\right]\left[\begin{array}{c}
\varepsilon_{0} \\
\hdashline \bar{\chi} \\
\hdashline \phi
\end{array}\right]
$$

where

$$
\begin{array}{ll}
\boldsymbol{N}=\left[N_{x}, N_{y}, N_{x y}\right]^{\mathrm{T}} ; & \varepsilon_{0}=\left[\varepsilon_{x_{0}}, \varepsilon_{y_{0}}, \varepsilon_{x y_{0}}\right]^{\mathrm{T}} ; \\
\boldsymbol{M}=\left[M_{x}, M_{y}, M_{x y}\right]^{\mathrm{T}} ; & \chi=\left[\chi_{x}, \chi_{y}, \chi_{x y}\right]^{\mathrm{T}} ; \\
\boldsymbol{Q}=\left[Q_{x}, Q_{y}\right]^{\mathrm{T}} ; & \boldsymbol{\phi}=\left[\boldsymbol{\phi}_{x}, \phi_{y}\right]^{\mathrm{T}} .
\end{array}
$$

In the above relations, $n$ is the number of layers and

$$
H_{i}=\left(h_{L+1}^{i}-h_{L}^{i}\right) / i, \quad i=1,2,3 .
$$

\section{Finite element formulation}

In the $\mathrm{C}^{\circ}$ finite element theory, the continuum displacement vector within the element is discretized such that

$$
a(x, y, t)=\sum_{i=1}^{\mathrm{NN}} N_{i}(x, y) a_{i}(t),
$$


in which the term $N_{i}(x, y)$ is the shape function associated with node $i, \mathrm{NN}$ is the number of nodes in the element, and $a_{i}(t)$ is the value of the displacement vector $a(x, y, t)$ corresponding to node $i$.

With the generalized displacement vector $a(x, y, t)$ at all points within the element, the generalized strain vector $\bar{\varepsilon}(x, y, t)$ at any point is expressed as follows:

$$
\bar{\varepsilon}(x, y, t)=\sum_{i=1}^{\mathrm{NN}} \boldsymbol{B}_{i}(x, y) \boldsymbol{a}_{i}(t)
$$

where

$$
\begin{aligned}
& \bar{\varepsilon}=\left(\varepsilon_{x 0}, \varepsilon_{y 0}, \varepsilon_{x y 0}, \chi_{x}, \chi_{y}, \chi_{x y}, \phi_{x}, \phi_{y}\right)^{\mathrm{T}}, \\
& \boldsymbol{a}_{i}=\left(u_{0 i}, v_{0 i}, w_{0 i}, \theta_{x i}, \theta_{y i}\right)^{\mathrm{T}} .
\end{aligned}
$$

$\boldsymbol{B}_{\mathrm{i}}$ is the strain-displacement matrix and is given as follows:

$$
\begin{aligned}
& B_{11}=B_{32}=B_{44}=B_{65}=B_{73}=\partial N_{i} / \partial x, \\
& B_{22}=B_{31}=B_{55}=B_{64}=B_{83}=\partial N_{i} / \partial y, \\
& B_{74}=B_{85}=N_{i} .
\end{aligned}
$$

With finite elements for the space discretization, the dynamic problem (in the absence of damping) gives rise to a set of ordinary differential equations of the form

$$
\boldsymbol{M a}(t)+\boldsymbol{K a}(t)=\boldsymbol{P}(t)
$$

in which the dots denote differentiation with respect to time, $t, a(t)$ is the nodal displacement vector, $\boldsymbol{M}$ is the mass matrix, and $\boldsymbol{P}(t)$ is the vector of nodal forces which varies with time, $t$. The elements of the stiffness matrix $K$ can readily be computed using the standard relation,

$$
\boldsymbol{K}_{i j}=\sum_{e=1}^{\mathrm{NE}} \boldsymbol{K}_{i j}^{e}=\sum_{e=1}^{\mathrm{NE}} \int_{-1}^{+1} \int_{-1}^{+1} \boldsymbol{B}_{i}^{\mathrm{T}} \boldsymbol{D} \boldsymbol{B}_{j}|\boldsymbol{J}| \mathrm{d} \xi \mathrm{d} \eta .
$$

The mass matrix $\boldsymbol{M}$ in equation (10) is given by

$$
\boldsymbol{M}=\sum_{e=1}^{\mathrm{NE}} \boldsymbol{M}^{e}=\sum_{e=1}^{\mathrm{NE}} \int_{\mathrm{Area}} \boldsymbol{N}^{\mathrm{T}} \boldsymbol{m} \boldsymbol{N} \mathrm{d} \boldsymbol{A},
$$

where

$$
\boldsymbol{m}=\left[\begin{array}{lllll}
I_{1} & & & & \mathbf{0} \\
& I_{1} & & & \\
& & I_{1} & & \\
& & & I_{2} & \\
\mathbf{0} & & & & I_{2}
\end{array}\right]
$$

and

$$
I_{1}, I_{2}=\sum_{L=1}^{n} \int_{h_{l}}^{h_{L+1}}\left(1, z^{2}\right) \rho^{L} \mathrm{~d} z .
$$

in which $I_{1}, I_{2}$ are normal inertia and rotary inertias respectively; $\rho^{L}$ is the material density of the $L$ th layer. 
The time integration scheme

As previously mentioned, the integration in time of equation (10) is performed using the explicit central difference time integration scheme. This scheme can be written as

$$
\boldsymbol{a}^{n+1}=\boldsymbol{M}^{-1}\left[(\Delta t)^{2}\left(-\boldsymbol{K} \boldsymbol{a}^{n}+\boldsymbol{P}^{n}\right)-\boldsymbol{M a ^ { n - 1 }}+2 \boldsymbol{M a ^ { n }}\right],
$$

where superscripts $n-1, n, n+1$ stand for three successive time stages and $\Delta t$ is the time step length. The main advantage of this approach is that if $\boldsymbol{M}$ is diagonal, the computation at each time step is trivial. Unfortunately, for the quadrilateral isoparametric plate elements used in the spatial discretization, $\boldsymbol{M}$ is not diagonal and a special mass lumping scheme is used to bring about the diagonalization of $\boldsymbol{M}$

A diagonal mass matrix that is more sophisticated than a lumped mass matrix can be derived from a consistent mass matrix and is discussed elsewhere [7].

After the mass matrix is diagonalised, equation (13a) can be rewritten as

$$
a_{i}^{n+1}=\left[(\Delta t)^{2} / M_{i i}\right]\left[-\sum_{j=1}^{m} K_{i j} a_{j}^{n}+P_{i}^{n}\right]-a_{i}^{n-1}+2 a_{i}^{n},
$$

where $m$ denotes the number of nodal variables. If values of $a^{0}$ and $\dot{a}^{0}$ are prescribed as initial conditions, a special starting algorithm can be written by noting that

$$
\dot{a}^{0}=\left(a^{1}-a^{-1}\right) / 2 \Delta t
$$

and eliminating $a^{-1}$ from equation (13b) leads to the expression

$$
a_{i}^{1}=\left(\Delta t^{2} / 2 M_{i i}\right)\left[-\sum_{j=1}^{\mathrm{NN}} K_{i j} a_{j}^{0}+P_{i}^{0}\right]+a_{i}^{0}+a_{i}^{0} \Delta t .
$$

\section{Numerical results and discussion}

In the present study the four-node linear, the eight-node serpendipity, and the nine-node Lagrangian quadrilateral isoparametric elements were employed. Since the element accounts for the transverse shear strains, reduced integration was employed to evaluate the shear terms numerically. That is, the $3 \times 3$ Gauss rule was used to integrate the bending and the inertia terms and the $2 \times 2$ Gauss rule was used to integrate the shear energy terms. All the computations were carried on a CYBER 180/840 Computer in single precision. Due to the biaxial symmetry of the problems discussed, only one quadrant of the plate was analysed except for angle-ply laminates, which are analysed as full plates. In all of the numerical examples presented herein, zero initial conditions were assumed.

The following three sets of data were used in obtaining the numerical results:

$$
a=b=25 \mathrm{~cm}, \quad q=10 \mathrm{~N} / \mathrm{cm}^{2}
$$

\section{Data 1.}

Face sheets [3]

$$
\begin{array}{ll}
E_{1}=1.308 \times 10^{7} \mathrm{~N} / \mathrm{cm}^{2}, & E_{2}=1.06 \times 10^{6} \mathrm{~N} / \mathrm{cm}^{2}, \\
G_{12}=G_{13}=6 \times 10^{5} \mathrm{~N} / \mathrm{cm}^{2}, & G_{23}=3.9 \times 10^{5} \mathrm{~N} / \mathrm{cm}^{2}, \\
\rho=1.58 \times 10^{-5} \mathrm{~N} \mathrm{~s}^{2} / \mathrm{cm}^{4}, & \nu=0.28 .
\end{array}
$$


Core [2]

$$
\begin{aligned}
& G_{23}=1.722 \times 10^{4} \mathrm{~N} / \mathrm{cm}^{2}, \quad G_{13}=5.206 \times 10^{4} \mathrm{~N} / \mathrm{cm}^{2}, \\
& \rho=1.009 \times 10^{-6} \mathrm{~N} \mathrm{~s}^{2} / \mathrm{cm}^{4} .
\end{aligned}
$$

Data 2 [20]

$$
\begin{array}{ll}
E_{2}=2.1 \times 10^{6} \mathrm{~N} / \mathrm{cm}^{2}, & E_{1} / E_{2}=25, \quad G_{12}=G_{23}=G_{13}=0.5 E_{2}, \\
\rho=8 \times 10^{-6} \mathrm{~N} \mathrm{~s}^{2} / \mathrm{cm}^{4}, & \nu=0.25 .
\end{array}
$$

\section{Data 3}

Face sheets [8]

$$
\begin{aligned}
& E_{x}=E_{y}=6.895 \times 10^{6} \mathrm{~N} / \mathrm{cm}^{2}, \quad \nu=0.33, \\
& G_{x y}=G_{y z}=G_{x z}=2.592 \times 10^{6} \mathrm{~N} / \mathrm{cm}^{2}, \\
& \rho=2.821 \times 10^{-5} \mathrm{~N} \mathrm{~s}^{2} / \mathrm{cm}^{4} .
\end{aligned}
$$

Core [8]

$$
\rho=1.242 \times 10^{-6} \mathrm{~N} \mathrm{~s}^{2} / \mathrm{cm}^{4},
$$

Case I: $G_{y z}=5.17 \times 10^{4} \mathrm{~N} / \mathrm{cm}^{2}, \quad G_{x z}=1.344 \times 10^{5} \mathrm{~N} / \mathrm{cm}^{2}$,

Case I: $G_{y z}=5.17 \times 10^{3} \mathrm{~N} / \mathrm{cm}^{2}, \quad G_{x z}=1.344 \times 10^{4} \mathrm{~N} / \mathrm{cm}^{2}$,

Case III: $\quad G_{y z}=5.17 \times 10^{2} \mathrm{~N} / \mathrm{cm}^{2}, \quad G_{x z}=1.344 \times 10^{3} \mathrm{~N} / \mathrm{cm}^{2}$.

$\nu_{12}=\left(E_{1} / E_{2}\right) \nu_{21}$; directions 1 and $x$ are coincident.
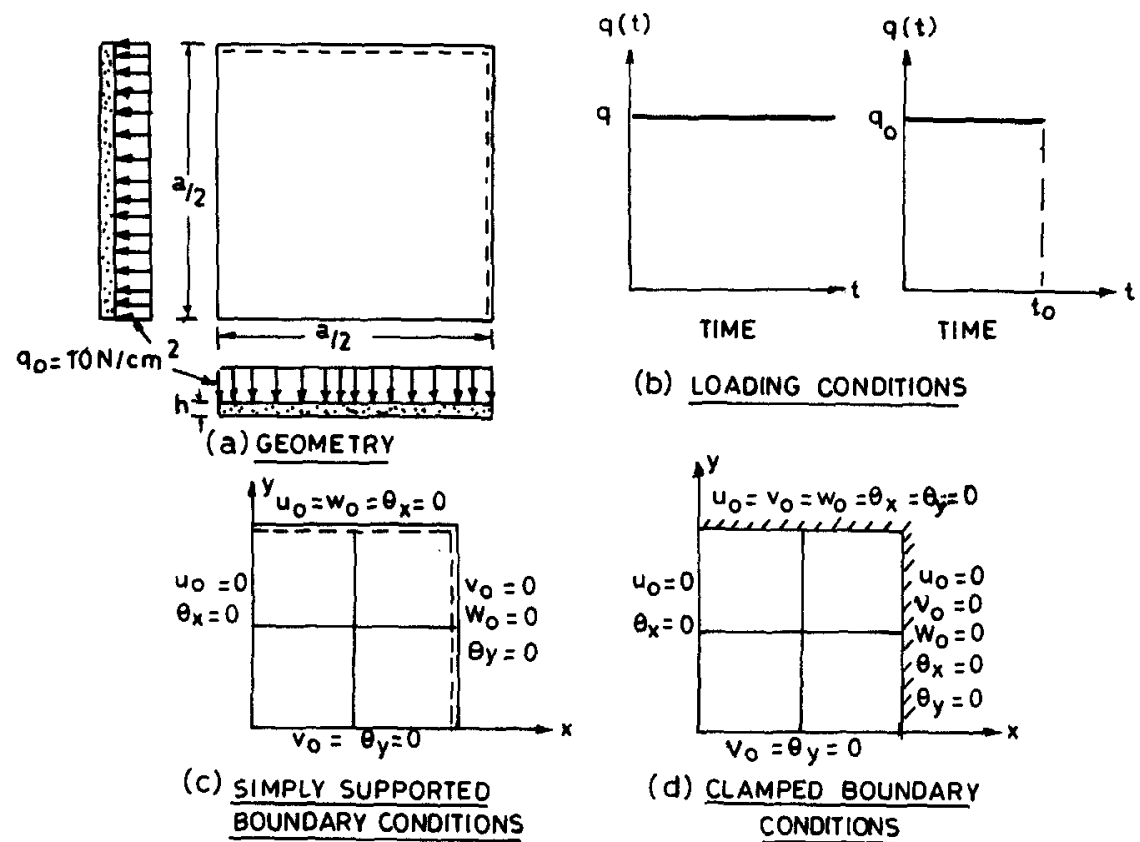

(b) LOADING CONDITIONS

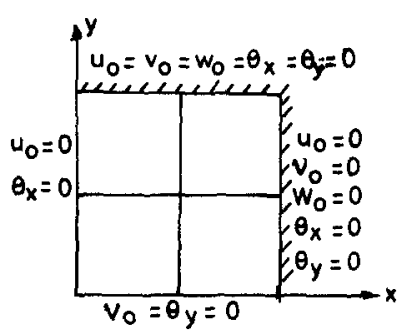

(d) CLAMPED BOUNDARY

Fig. 2. Geometry, loading and boundary conditions. 
Table 1

Convergence of centre deflection and stress for different time steps and meshes with 4-noded elements

\begin{tabular}{|c|c|c|c|c|c|c|c|c|c|c|}
\hline \multirow{2}{*}{$\begin{array}{l}\text { Time } \\
(\mu s)\end{array}$} & \multirow{2}{*}{$\begin{array}{l}w_{0} \times 10^{3} \\
\sigma_{x}^{\text {top }}\end{array}$} & \multicolumn{3}{|c|}{$\Delta t=4 \mu \mathrm{s}$} & \multicolumn{3}{|c|}{$\Delta t=5 \mu \mathrm{s}$} & \multicolumn{3}{|c|}{$\Delta t=10 \mu \mathrm{s}$} \\
\hline & & $2 \times 2$ & $3 \times 3$ & $4 \times 4$ & $2 \times 2$ & $3 \times 3$ & $4 \times 4^{a}$ & $2 \times 2$ & $3 \times 3^{a}$ & $4 \times 4^{a}$ \\
\hline \multirow[t]{2}{*}{40} & $w_{0}$ & 0.2340 & 0.2350 & 0.2348 & 0.2339 & 0.2349 & & 0.2337 & & \\
\hline & $\sigma_{x}$ & 51.656 & 50.548 & 48.656 & 51.847 & 50.621 & & 53.458 & & \\
\hline \multirow[t]{2}{*}{80} & $w_{0}$ & 0.9538 & 1.0019 & 1.0259 & 0.9541 & 1.0024 & & 0.9569 & & \\
\hline & $\sigma_{x}$ & 181.22 & 204.32 & 215.45 & 181.15 & 204.90 & & 181.46 & & \\
\hline \multirow[t]{2}{*}{120} & $w_{0}$ & 1.8251 & 1.8784 & 1.8843 & 1.8256 & 1.8788 & & 1.8302 & & \\
\hline & $\sigma_{x}$ & 345.14 & 387.96 & 404.82 & 344.72 & 387.03 & & 340.67 & & \\
\hline \multirow[t]{2}{*}{160} & $w_{0}$ & 2.1375 & 1.9669 & 1.9163 & 2.1372 & 1.9661 & & 2.1345 & & \\
\hline & $\sigma_{x}$ & 403.84 & 420.81 & 418.09 & 404.25 & 420.59 & & 404.54 & & \\
\hline \multirow[t]{2}{*}{200} & $w_{0}$ & 1.6977 & 1.5661 & 1.5438 & 1.6970 & 1.5666 & & 1.6905 & & \\
\hline & $\sigma_{x}$ & 329.63 & 340.02 & 346.97 & 330.25 & 340.51 & & 337.67 & & \\
\hline
\end{tabular}

Data 1,5 layers, $0^{\circ} / 90^{\circ} /$ core $/ 0^{\circ} / 90^{\circ}, h_{0}=h_{90}=0.5, h_{\text {core }}=3.0, a / h=5$

anstable

In order to investigate the numerical convergence and accuracy of the transient behaviour of the composite sandwich plate, a simply supported plate with a suddenly applied uniform pulse loading was analysed using Data 1 . The plate geometry, a typical finite element mesh, boundary conditions of the quarter model, and applied loading are shown in Fig. 2. The estimate of the critical time step is crucial in transient analysis of composite sandwich plates. Tables 1, 2, and 3 present center deflection and normal stress of 4-, 8-, and 9-noded elements, respectively, for different meshes and time steps. From these tables it is found that the safe estimate of the critical time step length given by Leech [13], and Tsui and Tong [26] are valid only for isotropic plates. The estimate of the critical time step length given by Tsui and Tong [26] is used with minor modification in this study. It is thus given as

$$
\Delta t \leqslant L_{e}\left[\frac{\rho\left(1-\nu^{2}\right) / E_{2} R}{2+0.83(1-\nu)\left(1+1.5\left(L_{e} / h\right)\right)^{2}}\right]^{1 / 2},
$$

Table 2

Convergence of centre deflection and stress for different time steps and meshes with 8-noded elements

\begin{tabular}{|c|c|c|c|c|c|c|c|c|c|c|}
\hline \multirow{2}{*}{$\begin{array}{l}\text { Time } \\
(\mu \mathrm{s})\end{array}$} & \multirow{2}{*}{$\begin{array}{l}w_{0} \times 10^{3} \\
\sigma_{x}^{\text {top }}\end{array}$} & \multicolumn{3}{|c|}{$\Delta \mathrm{t}=0.5 \mu \mathrm{s}$} & \multicolumn{3}{|c|}{$\Delta t=1 \mu \mathrm{s}$} & \multicolumn{3}{|c|}{$\Delta t=2 \mu \mathrm{s}$} \\
\hline & & $2 \times 2$ & $3 \times 3$ & $4 \times 4$ & $2 \times 2$ & $3 \times 3$ & $4 \times 4$ & $2 \times 2$ & $3 \times 3^{a}$ & $4 \times 4^{a}$ \\
\hline \multirow[t]{2}{*}{40} & $w_{0}$ & 0.1573 & 0.2353 & 0.2487 & 0.1569 & 0.2346 & 0.2489 & 0.1553 & & \\
\hline & $\sigma_{x}$ & 41.851 & 42.349 & 45.686 & 41.805 & 42.382 & 45.661 & 41.535 & & \\
\hline \multirow[t]{2}{*}{80} & $w_{0}$ & 1.0532 & 1.0679 & 1.0638 & 1.0536 & 1.0669 & 1.0661 & 1.0556 & & \\
\hline & $\sigma_{x}$ & 228.62 & 227.34 & 227.22 & 228.71 & 227.23 & 227.47 & 229.07 & & \\
\hline \multirow[t]{2}{*}{120} & $w_{0}$ & 1.9578 & 1.8598 & 1.8680 & 1.9578 & 1.8587 & 1.8685 & 1.9574 & & \\
\hline & $\sigma_{x}$ & 440.25 & 430.63 & 424.65 & 440.20 & 430.32 & 424.53 & 439.85 & & \\
\hline \multirow[t]{2}{*}{160} & $w_{0}$ & 1.9208 & 1.8650 & 1.8917 & 1.9199 & 1.8644 & 1.8943 & 1.9164 & & \\
\hline & $\sigma_{x}$ & 425.16 & 425.41 & 424.73 & 425.01 & 425.08 & 425.33 & 424.37 & & \\
\hline \multirow[t]{2}{*}{200} & $w_{0}$ & 1.4901 & 1.5270 & 1.5189 & 1.4922 & 1.5289 & 1.5171 & 1.5009 & & \\
\hline & $\sigma_{x}$ & 345.64 & 357.19 & 359.18 & 345.86 & 357.27 & 359.48 & 346.97 & & \\
\hline
\end{tabular}

Data 2, 5 layers, $0^{\circ} / 90^{\circ} /$ core $/ 0^{\circ} / 90^{\circ}, h_{0}=h_{90}=0.5, h_{\text {core }}=3.0, a / h=5$

a Unstable 
Table 3

Convergence of centre deflection and stress for different time steps and meshes with 9-noded elements

\begin{tabular}{|c|c|c|c|c|c|c|c|c|c|c|}
\hline \multirow{2}{*}{$\begin{array}{l}\text { Time } \\
(\mu s)\end{array}$} & \multirow{2}{*}{$\begin{array}{l}w_{0} \times 10^{3} \\
\sigma_{x}^{\text {top }}\end{array}$} & \multicolumn{3}{|c|}{$\Delta t=0.5 \mu \mathrm{s}$} & \multicolumn{3}{|c|}{$\Delta t=1 \mu \mathrm{s}$} & \multicolumn{3}{|c|}{$\Delta t=2 \mu \mathrm{s}$} \\
\hline & & $2 \times 2$ & $3 \times 3$ & $4 \times 4$ & $\overline{2 \times 2}$ & $3 \times 3$ & $4 \times 4$ & $2 \times 2$ & $3 \times 3$ & $\overline{4 \times 4^{a}}$ \\
\hline \multirow[t]{2}{*}{40} & $w_{0}$ & 0.2344 & 0.2343 & 0.2346 & 0.2344 & 0.2343 & 0.2345 & 0.2343 & 0.2343 & \\
\hline & $\sigma_{x}$ & 45.419 & 45.093 & 45.510 & 45.418 & 45.099 & 45.487 & 45.412 & 45.142 & \\
\hline \multirow[t]{2}{*}{80} & $w_{0}$ & 1.0779 & 1.0784 & 1.0798 & 1.0780 & 1.0785 & 1.0800 & 1.0784 & 1.0791 & \\
\hline & $\sigma_{x}$ & 236.14 & 234.72 & 234.54 & 236.24 & 234.77 & 234.59 & 236.65 & 235.09 & \\
\hline \multirow[t]{2}{*}{120} & $w_{0}$ & 1.8508 & 1.8531 & 1.8473 & 1.8507 & 1.8531 & 1.8471 & 1.8505 & 1.8530 & \\
\hline & $\sigma_{x}$ & 425.06 & 422.86 & 418.83 & 424.98 & 422.83 & 418.78 & 425.05 & 422.81 & \\
\hline \multirow[t]{2}{*}{160} & $w_{0}$ & 1.8947 & 1.8925 & 1.8923 & 1.8946 & 1.8926 & 1.8922 & 1.8944 & 1.8931 & \\
\hline & $\sigma_{x}$ & 424.74 & 422.96 & 422.24 & 424.53 & 422.91 & 421.99 & 423.61 & 422.50 & \\
\hline \multirow[t]{2}{*}{200} & $w_{0}$ & 1.5279 & 1.5192 & 1.5247 & 1.5281 & 1.5192 & 1.5248 & 1.5286 & 1.5197 & \\
\hline & $\sigma_{x}$ & 368.00 & 364.94 & 366.39 & 368.02 & 364.93 & 366.25 & 367.57 & 364.96 & \\
\hline
\end{tabular}

Data 2, 5 layers, $0^{\circ} / 90^{\circ} /$ core $/ 0^{\circ} / 90^{\circ}, h_{0}=h_{90}=0.5, h_{\text {core }}=3.0, a / h=5$

anstable.

where $R=E_{1} / E_{2}, L_{\mathrm{e}}$ is the smallest distance between adjacent nodes in any element used. The solution obtained by using a four-node element with $\Delta t=4 \mu \mathrm{s}$, and eight- and nine-node elements with $\Delta t=1 \mu \mathrm{s}$ is found suitable for all cases.

Table 4

Comparison of transverse deflections $w_{0} \times 10^{3}(\mathrm{~cm})$ obtained in the present study with those obtained by the classical plate theory (CPT) and closed-form solution (CFS) [20] for a composite square plate (Data 2, $a / h=5$ ) under suddenly applied sinusoidal pulse load

\begin{tabular}{|c|c|c|c|c|c|c|c|c|c|}
\hline \multicolumn{2}{|c|}{ Lamination scheme ${ }^{a}$} & \multicolumn{8}{|l|}{ Layers } \\
\hline & & 1 & 2 & 3 & 4 & 5 & 6 & 7 & 8 \\
\hline $\mathrm{CP}, R=25$ & $\begin{array}{l}\text { Present } \\
\text { CFS } \\
\text { CPT }\end{array}$ & $\begin{array}{l}0.3582 \\
(85) \\
0.3566 \\
(90) \\
0.1272 \\
(55)\end{array}$ & $\begin{array}{l}0.4606 \\
(98) \\
0.4604 \\
(100) \\
0.3153 \\
(85)\end{array}$ & $\begin{array}{l}0.3399 \\
(83) \\
0.3386 \\
(85) \\
0.1272 \\
(55)\end{array}$ & $\begin{array}{l}0.2951 \\
(77) \\
0.2947 \\
(80) \\
0.1493 \\
(60)\end{array}$ & $\begin{array}{l}0.2929 \\
(77) \\
0.2924 \\
(80) \\
0.1272 \\
(55)\end{array}$ & $\begin{array}{l}0.2815 \\
(75) \\
0.2809 \\
(80) \\
0.1366 \\
(55)\end{array}$ & $\begin{array}{l}0.2825 \\
(75) \\
0.2817 \\
(80) \\
0.1272 \\
(55)\end{array}$ & $\begin{array}{l}0.2776 \\
(75) \\
0.2765 \\
(80) \\
0.1325 \\
(55)\end{array}$ \\
\hline $\mathrm{CP}, R=40$ & $\begin{array}{l}\text { Present } \\
\text { CFS }\end{array}$ & $\begin{array}{l}0.3243 \\
(82) \\
0.3233 \\
(85)\end{array}$ & $\begin{array}{l}0.3833 \\
(89) \\
0.3824 \\
(90)\end{array}$ & $\begin{array}{l}0.2993 \\
(78) \\
0.2985 \\
(80)\end{array}$ & $\begin{array}{l}0.2448 \\
(70) \\
0.2438 \\
75)\end{array}$ & $\begin{array}{l}0.2473 \\
(70) \\
0.2473 \\
(75)\end{array}$ & $\begin{array}{l}0.2352 \\
(68) \\
0.2352 \\
(70)\end{array}$ & $\begin{array}{l}0.2376 \\
(69) \\
0.2376 \\
(70)\end{array}$ & $\begin{array}{l}0.2323 \\
(68) \\
0.2323 \\
(70)\end{array}$ \\
\hline AP, $R=25$ & $\begin{array}{l}\text { Present } \\
\text { CFS }\end{array}$ & & $\begin{array}{l}0.3394 \\
(84) \\
0.3387 \\
(85)\end{array}$ & & $\begin{array}{l}0.2283 \\
(67) \\
0.2277 \\
(70)\end{array}$ & & $\begin{array}{l}0.2205 \\
(66) \\
0.2196 \\
(70)\end{array}$ & & $\begin{array}{l}0.2180 \\
(66) \\
0.2170 \\
(70)\end{array}$ \\
\hline $\mathrm{AP}, R=40$ & $\begin{array}{l}\text { Present } \\
\text { CFS }\end{array}$ & & $\begin{array}{l}0.2830 \\
(76) \\
0.2826 \\
(80)\end{array}$ & & $\begin{array}{l}0.1986 \\
(63) \\
0.1977 \\
(65)\end{array}$ & & $\begin{array}{l}0.1932 \\
(62) \\
0.1922 \\
(65)\end{array}$ & & $\begin{array}{l}0.1915 \\
(62) \\
0.1885 \\
(65)\end{array}$ \\
\hline
\end{tabular}

Values between parentheses denote the time (in $\mu \mathrm{s}$ ) at which the maximum centre deflection occurred

${ }^{2} \mathrm{CP}=$ cross-ply $\left(0^{\circ} / 90^{\circ} / 0^{\circ} / \ldots\right) ; \mathrm{AP}=$ angle-ply $\left(45^{\circ} /-45^{\circ} / 45^{\circ} / \ldots\right) ; R=E_{1} / E_{2} ; q_{0}=10 \mathrm{~N} / \mathrm{cm}^{2}$. Boundary conditions used for angle-ply laminates are the same as given in [20] 


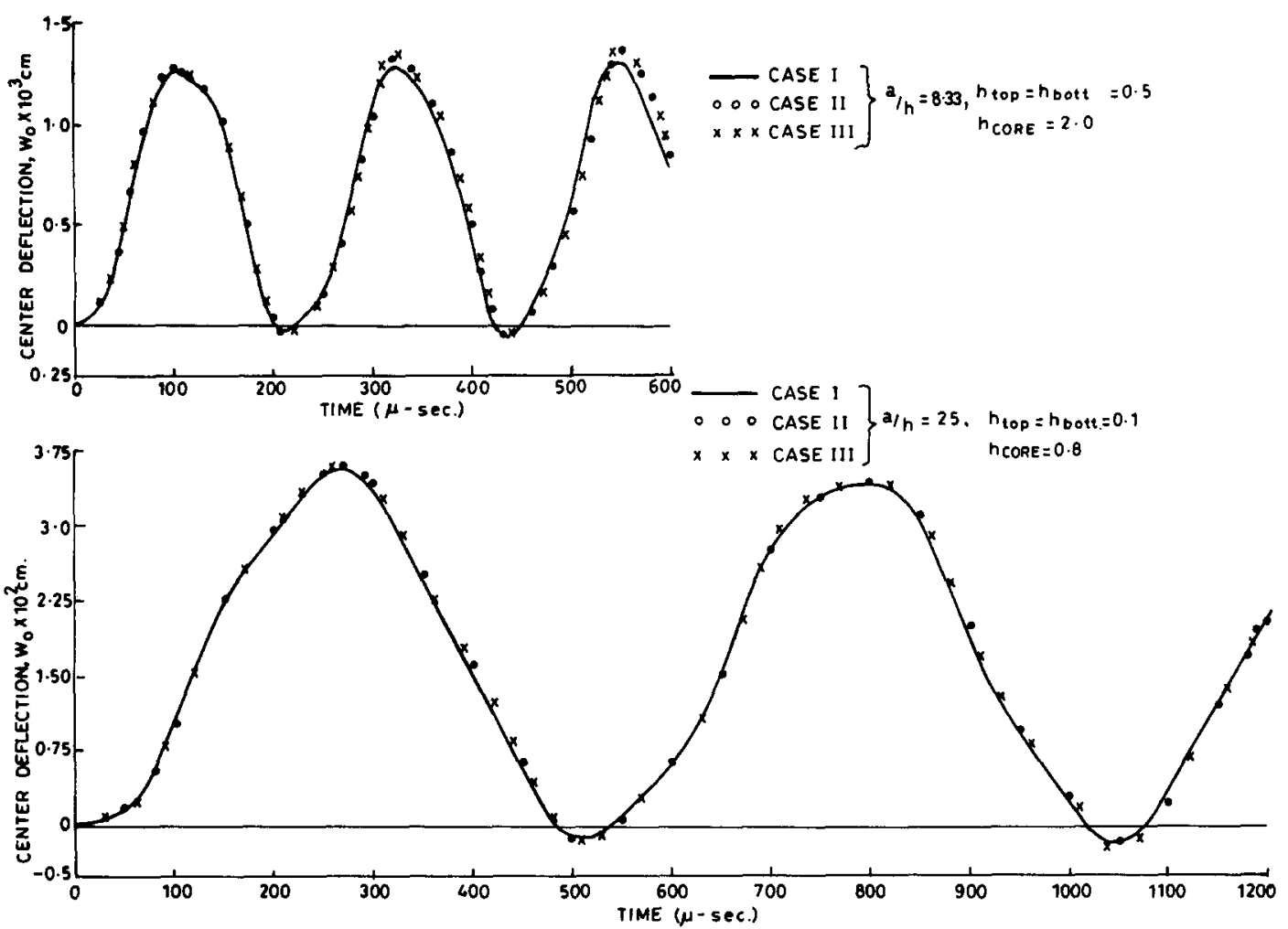

Fig. 3. Effect of shear and side-thickness ratio on the transient response of a three-layer clamped, square plate subjected to suddenly applied pulse loading (Data $3, \Delta t=2 \mu \mathrm{s}$ ).

In order to validate the present element, a problem for which the analytical solution exists is solved. The problem consists of a simply supported square plate (with Data 2) subjected to a suddenly applied sinusoidally distributed pulse loading. A comparison of the effect of layers, shear deformation, lamination scheme, and orthotropy on the center transverse deflection obtained by the present element and by the closed-form solution [20] is shown in Table 4. It is seen that classical plate theory predicts significantly lower values of the deflection and the period. Since the present finite element solution is in excellent agreement with the exact solution, the $2 \times 2$ mesh with a nine-noded Lagrangian element was used in all of the problems to be discussed.

The effect of shear modulii of core materials and side-thickness ratio on the transient response of a three-layer clamped, square plate subjected to a suddenly applied uniform pulse loading (Data 3) is shown in Fig. 3. Although the effect of transverse shear modulii ( $G_{y z}$ and $G_{x z}$ ) of core material is not prominent, the deflection and period decrease with increasing thickness of the plate. The effect of plate thickness on the amplitude and period of the deflection is clear.

Figures 4 and 5 show plots of center deflection and normal stress for a five-layer simply supported plate (Data 1). From these figures, it is found that the effect of transverse shear modulii of stiff layers is very significant on the transient behaviour of sandwich plates. The composite sandwich plate, neglecting transverse shear modulii of stiff layers predicts higher values of deflection, period, and stresses. The effect of transverse shear modulii of stiff layers on the transient response of a sandwich plate is clear.

The material properties of Data 2 for facings and core material properties of Data 1 with a full plate model were used in the following example. To further investigate the effect of the 


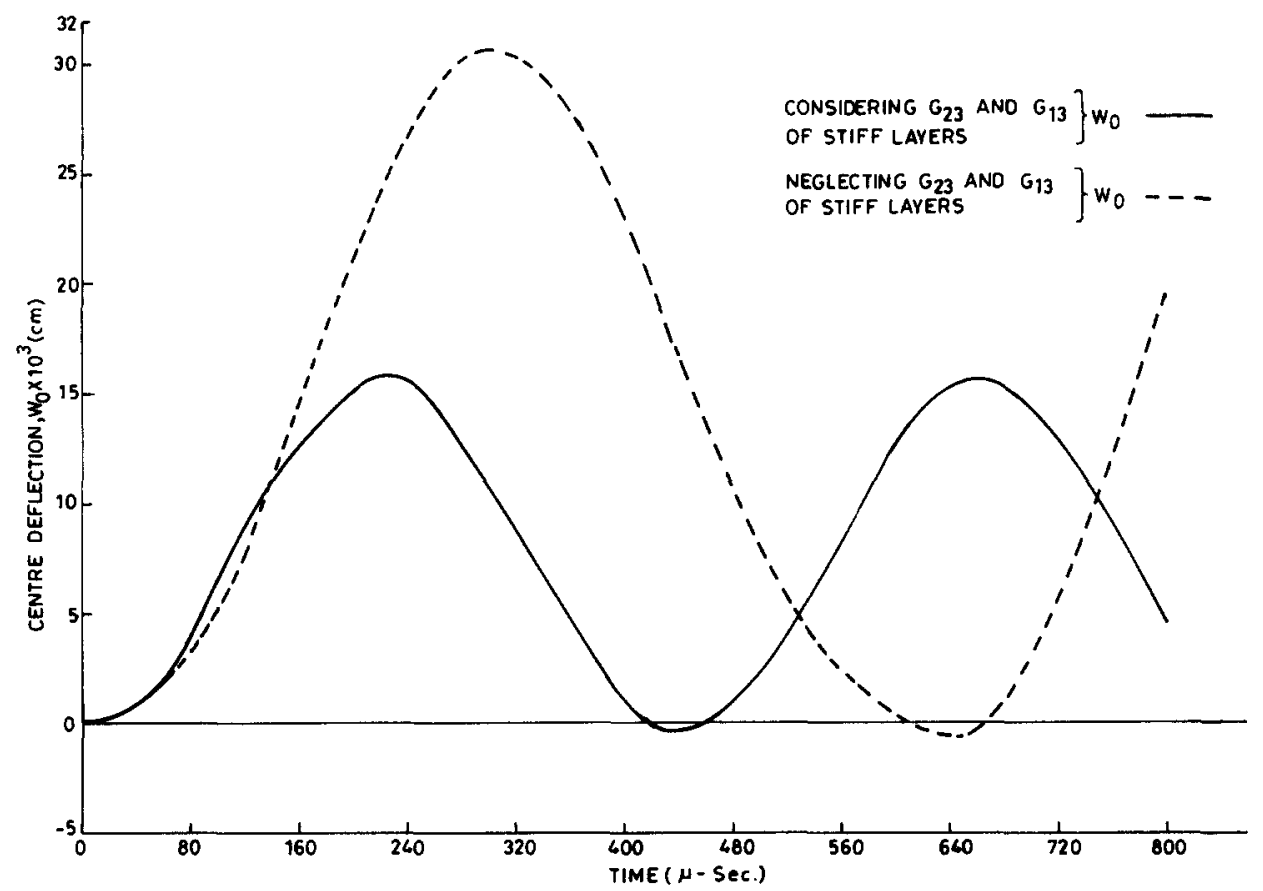

Fig. 4. Effect of transverse shear moduli of stiff layers on the transient response of five-layer $\left(0^{\circ} / 90^{\circ} / \mathrm{core} / 90^{\circ} / 0^{\circ}\right)$ simply supported plates under suddenly applied pulse loading (Data $1, \Delta t=2 \mu \mathrm{s}, a / h=10, h_{0}=h_{90}=0.125$, $h_{\text {core }}=2.0$ ).

angle and material orthotropy on the center transverse deflection and normal stress, a simply supported plate subjected to a suddenly applied sinusoidal loading was analysed by considering the full plate model (Fig. 6). The effects on the amplitude and period of the deflections and

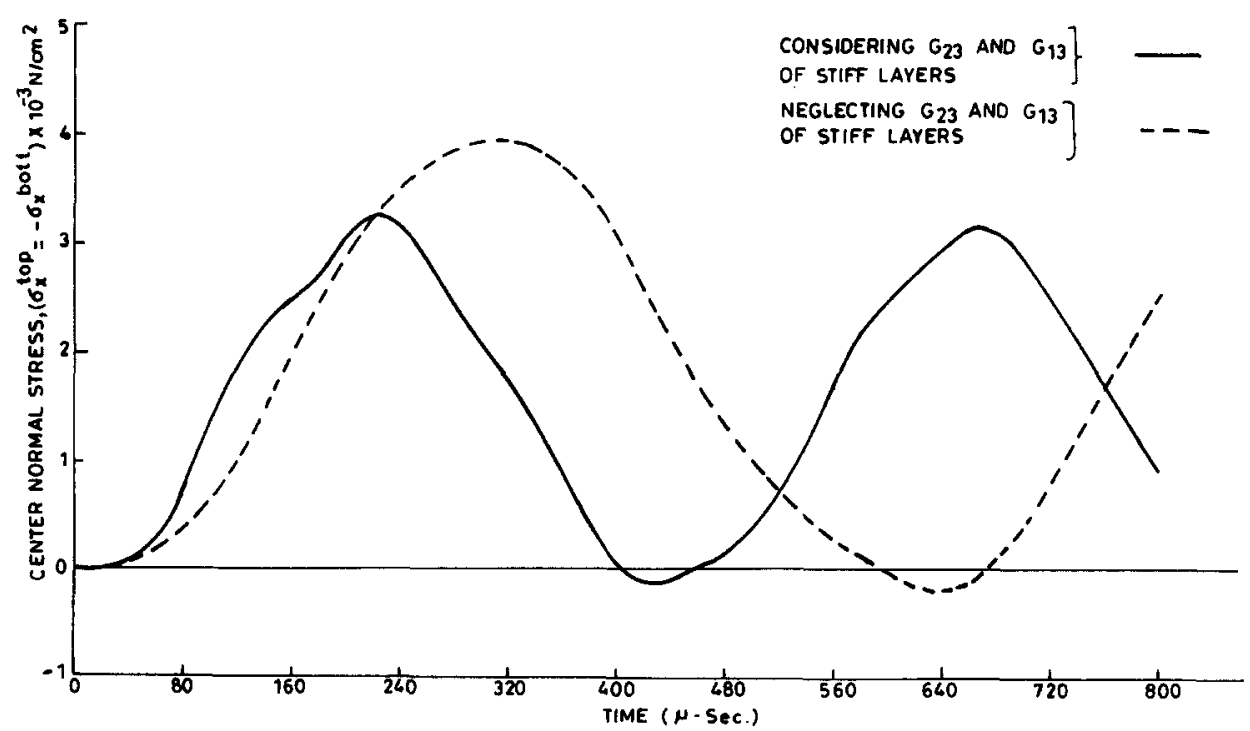

Fig. 5. Center normal stress versus time for five-layer $\left(0^{\circ} / 90^{\circ} /\right.$ core $\left./ 90^{\circ} / 0^{\circ}\right)$ simply supported plates under pulse loading (Data $1, \Delta t=2 \mu \mathrm{s}, a / h=10$ ). 


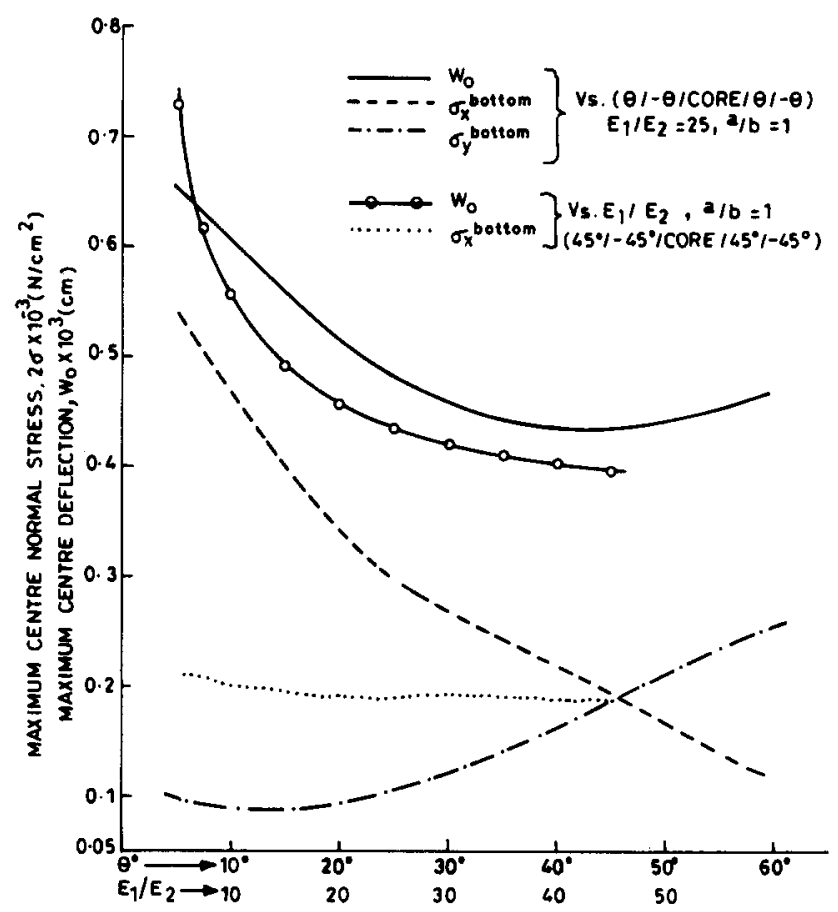

Fig. 6. Effect of lamination angle and material orthotropy on the solution of five-layer simply supported plates under suddenly applied sinusoidal loading (Data $1, \Delta t=1 \mu \mathrm{s}, 4 \times 4$ full plate, $h_{\theta}=0.5, h_{\text {core }}=3.0, a / h=5$ ).

stresses are clearly nonlinear. Since no damping or internal friction is included in the present model, the solutions do not decay with time.

\section{Conclusions}

Numerical results of the transient dynamic analysis of composite sandwich plates based on Mindlin's theory are presented. The shear flexible element employed herein is stable and accurate in predicting the transient response of sandwich plates. The transverse shear rigidity modulii of stiff layers on the transient response of sandwich plates are significant. All of the results presented herein for sandwich plates must be validated by an independent investigation. However, on the basis of the excellent agreement of the present results with analytical results for generally orthotropic plates, it is fair to say that the element is accurate in predicting the transient response of composite sandwich plates.

The extension of these analyses to nonlinear (large rotations) transient response of composite sandwich plates is awaiting attention. An accurate prediction of the wave propagation in composites can be made only if a three-dimensional theory of inhomogeneous plates is used. The analysis presented here can also be extended to certain shell problems.

\section{Acknowledgement}

Partial support of this research by the Aeronautics Research and Development Board, Ministry of Defence, Government of India through its Grant No. Aero/RD-134/100/84$85 / 362$ is gratefully acknowledged. 


\section{References}

[1] AHMED, K.M., "Static and dynamic analysis of sandwich structures by the method of finite elements", J. Sound Vib. 18, pp. 75-91, 1971.

[2] Allen, H.C., Analysis and Design of Structural Sandwich Panels, Pergamon Press, London, 1969.

[3] Chirns, D.S. and P.A. Lagace, “Thick composite plates subjected to lateral loading”, J. Appl. Mech. 54, pp. 611-616, 1987.

[4] Habip, L.M., "A review of recent Russian work on sandwich construction", Int. J. Appl. Mech. Sci. 6, pp. $381-390,1951$.

[5] HABIP, L.M., "A survey of modern developments in the analysis of sandwich structures", Appl. Mech. Rev. 18, pp. 93-98, 1965.

[6] HiNroN, E., "The flexural analysis of laminated composites using a parabolic isoparametric plate bending element", Int. J. Num. Meth. Eng. 11, pp. 174-179, 1977.

[7] Hinton, E., R.Rock and O.C. ZiENKIEWICZ, "A note on mass lumping and related processes in the finite element method", Earthquake Eng. Struct. Dyn. 4, pp. 245-249, 1976.

[8] IU, V.P., Y.K. ChEUNG and S.L. LAU, "Nonlinear vibration analysis of multilayer beams by incremental finite elements-I: Theory and numerical formulation", J. Sound Vib. 100, pp. 359-372, 1985.

[9] JoNEs, R.M., Mechanics of Composite Materials, McGraw-Hill, New York, 1975.

[10] KaNT, T. and N.P. SAHANI, "Fibre reinforced plates-Some studies with a 9-noded Lagrangian/Hetarosis element", Trans. 8th Int. Conf. Struct. Mech. Reactor Tech. SMIRT-8, Paper 88/7, pp. 315-320, 1985.

[11] Khatua, T.P. and Y.K. Cheung, "Triangular element for multilayer sandwich plates", J. Eng. Mech. Div. ASCE 98, pp. 1225-1238, 1972.

[12] Khatua, T.P. and Y.K. Cheung, "Bending and vibration of multilayer sandwich beams and plates", Int. J. Num. Meth. Eng. 14, pp. 942-945, 1979.

[13] LEECH, J.W., "Stability of finite difference equations for transient response of flat plates", $A I A A J .3(9)$, pp. $1772-1773,1965$.

[14] Mindlin, R.D., "Influence of rotary inertia and shear on flexural motions of isotropic elastic plates", J. Appl. Mech. 18, pp. 31-38, 1951.

[15] Monforton, G.R. and L.A. Schmitr, "Finite element analysis of sandwich plates and cylindrical shell with laminated faces”, Proc. Conf. Matrix Method Struct. Mech., Wright Patterson Air Force Base, Ohio, pp. 573-616, 1969.

[16] Noor, A.K. and M.D. MATHERs, "Anisotropy and shear deformation in laminated composite plates", $A I A A J .14$, pp. 282-285, 1976.

[17] PaGano, N.J., "Exact solutions for rectangular bidirectional composites and sandwich plates”, J. Compos. Mater. 4, pp. 20-34, 1970.

[18] Panda, S.C. and R. NataraJ, "Finite element analysis of laminated composite plates", Int. J. Num. Meth. Eng. 14, pp. 69-79, 1979.

[19] Plantema, F.J., Sandwich Construction, John Wiley, New York, 1966.

[20] REDDY, J.N., "On the solutions to forced motion of rectangular composite plates", J. Appl. Mech. 49, pp. 403-408, 1982.

[21] REISSNER, E., "The effect of transverse shear deformation on the bending of elastic plates", J. Appl. Mech. 12, pp. A69-A77, 1945.

[22] Reissner, E., "On bending of elastic plates", Q. Appl. Math. 5, pp. 55-68, 1947.

[23] Reissner, E., "Finite deflections of sandwich plates", J. Aerosp. Sci. 15, pp. 435-440, 1948.

[24] Reissner, E., "Finite deflections of sandwich plates", J. Aerosp. Sci. 17, p. 125, 1950.

[25] . Timoshenko, S., Vibration Problems in Engineering, 2nd edn., Constable, London, 1937.

[26] TsUI, T.Y. and P. ToNG, "Stability of transient solution of moderately thick plates by finite difference methods", AIAA J. 9, pp. 2062-2063, 1971.

[27] YU, Y,Y., "A new theory of elastic sandwich plates-One dimensional case", J. Appl. Mech. 26, pp. 414-421, 1959.

[28] YU, Y.Y., "Forced flexural vibrations of sandwich plates in plane strain", J. Appl. Mech. 27, pp. 535-540, 1960.

[29] YU, Y.Y., "Flexural vibrations of elastic sandwich plates", J. Aerosp. Sci. 27, pp. 272-282, 1960.

[30] YU, Y.Y., "Simplified vibration analysis of elastic sandwich plates", J. Aerosp. Sci. 27, pp. 894-900, 1960. 